\title{
Determination of breeding season of endangered riverine catfish rita (Rita rita Hamilton, 1822) by studying ovarian development and Gonado-Somatic-Index
}

\author{
M. L. Rahman* and M. F. A. Mollah \\ Department of Fisheries Biology \& Genetics, Bangladesh Agricultural University; Mymensingh-2202, Bangladesh \\ *E-mail: Irgolap_bau@yahoo.com
}

\begin{abstract}
Rita rita is an endangered riverine catfish having high market and nutritive values. The histological process of ovaries of Rita rita were performed to determine the breeding season for facilitating the artificial breeding in controlled environment. Fish were sampled monthly from the Brahmaputra River adjacent to Bangladesh Agricultural University (BAU), Mymensingh. The average Gonado-Somatic Index (GSI) ranged from 0.14 to 0.60 with the highest GSI value of 0.60 in July. The highest fecundity of $60114 \pm 3207.88$ was found in the fish having length of $38.91 \pm 0.59 \mathrm{~cm}$ and weight of $1081.35 \pm 74.52 \mathrm{~g}$. In contrast, the lowest fecundity was $37307.2 \pm 154.57$ having length of $31.98 \pm 1.63 \mathrm{~cm}$ and weight of $810.87 \pm 49.75 \mathrm{~g}$. The fecundity was found to increase with the increase of total length, body weight and the ovary weight and the relationship was linear and significant among them. Six developmental stages of ovaries were observed and categorized as the synchronous group. Vitellogenesis began in April with full development of ovaries in July. From this study, it can be presumed that gonadal development of $R$. rita peaked in July and breeding time within the months of June and July.
\end{abstract}

Keywords: Histology, Rita rita, Gonad, Gonado-somatic index

\section{Introduction}

The catfish Rita rita (Hamilton, 1822) is greenish brown carnivorous fish widely distributed in South Asia. It is one of the critically endangered species in Bnagladesh (IUCN, 2003). The abundance of this species has been reported to decline day by day due to over-exploitation and various ecological changes in the natural aquatic ecosystem (Devi et al. 1991).

Knowledge on gonadal development and the spawning season of a species is necessary to determine the spawning frequency of its population as well as to establish a suitable induced breeding technique. The study of Gonado-Somatic Index (GSI) determines the state of maturity in terms of gonadal development and onset of spawning season. However, very few literatures are available on fecundity and GSI of $R$. rita. Although, monthly changes in the ovaries have been examined in some related species including brackish water catfish Plotosus canius (Khan et al., 2002), Mystus gulio (Sarker et al., 2002), Clarias batrachus (Faruq et al., 1996). A detail understanding of the gonadal development of a fish species is also considered an important step for the fish culturists. Histological observation may indicate the gonadal maturation and spawning season of a species.

Fecundity and gonadosomatic index have been useful tools to determine suitable spawning season of a particular species. The fecundity of fish can be estimated by actual counting method which is supposed to be the most accurate, but is very tedious, time consuming and to certain extent rather impossible for highly fecund fishes. Approximate fecundity is other olternative, which can be obtained by one of the following methods a) Volumetric method b) Gravimetric method c) Von vayer method as outlined by Lagler (1956). Gravimetric method was found to be more efficient than those of other methods and provided fairly accurate results (Islam and Hossain, 1990).

This species could be additional source of animal protein for local consumption, but it would have to be grown in controlled area like hatcheries, using low cost production methodology. To establish the induced breeding technique and culture in controlled environments of this riverine catfish, it is essential to know about its breeding biology and season.

In this present study fecundity and GSI was examined and breeding season was determined observing the gonadal development using histological process. 


\section{Materials and Methods}

\section{Study area and duration}

The samples of $R$. rita (Hamilton, 1822) were collected from the old Brahmaputra river adjacent to BAU campus, Mymensingh. At least five females were collected every month during first year study period. The total length and body weight of individual fish were measured first and then the ovary of each fish was taken out carefully and weighed using a sensitive portable electronic balance (Denver Instrument, XP-300; $3000 \times 0.1 \mathrm{~g}$ ) to estimate GSI. Finally ovaries were preserved in $10 \%$ buffered formalin for further study. The GSI is frequently applied to determine the spawning frequency of fishes and calculated according to the following formula:

$$
\text { GSI }=\frac{\text { Weight of gonad }}{\text { Weight of body }} \times 100
$$

\section{Fecundity estimation}

In this method, $20 \mathrm{mg}$ sample of ovary was taken separately from anterior, middle and posterior portions of each ovarian lobe accurately. The number of mature and maturing eggs from each portion was found out separately by actual counting due to small amount. The mean number of eggs in $20 \mathrm{mg}$ sample was determined and then multiplied by the total weight of the ovary, which gave the total number of eggs i.e. the absolute fecundity of respective fish. The relative fecundity also are calculated by absolute fecundity/body weight.

\section{Histology of gonad}

The preserved ovaries were taken out in a perforated plastic holder covering by perforated steel plates. Cleaning, infiltration and dehydration process were carried out in an automatic tissue processor unit using a series of alcohol of increasing concentrations, two times changes of xylene and finally through molten wax (three series).

Paraffin embedded blocks were cut by microtome knife at 4-5 $\mu \mathrm{m}$ size and left the sections into a water bath at a temperature of $40^{\circ} \mathrm{C}$. The sections were placed on a glass slide and kept overnight on a slide drier hot plate at a temperature of $20^{\circ} \mathrm{C}$. Then the sections were stained routinely with haematoxyline and eosin (Humason, 1972).

\section{Microscopic examination of the gonadal tissue}

The stained sections were mounted on the glass slide with Canada balsam and covered by cover slips and studied under a compound microscope (SWIFT M 4000-D). The photographic records were done simultaneously to study the different maturation stages oocyte and monthly developmental variations of ovary.

\section{Data analysis}

Microsoft Excel (2003) was used to determine linear relationship and correlation co-efficient ( $r$ ) between total length and fecundity, body weight and fecundity, gonad weight and fecundity following Zar (1984).

\section{Results}

\section{The female reproductive system}

The morphology of the ovary: The ovaries of $R$. rita were paired tubular organs lying dorsal to the alimentary canal and ventral to the swim bladder. They were attached to the body cavity by the mesovarium. A posterior extension of tunica albuginae united both ovaries forming an oviduct opened to the exterior via the oval shaped urogenital papilla. They were usually equal in size but occasionally one was larger than the other. 
Gonado-Somatic Index of $\boldsymbol{R}$. rita: The GSI, the indicator of the status of gonadal development and maturity of individuals of experimental species, was calculated for female $R$. rita from January to December. Month wise changes in mean GSI values of female $R$. rita are presented in Fig. 1 . Values of GSI ranged from $0.14 \pm 0.02$ to $0.57 \pm 0.04$. The higher values of GSI were observed during May to July ranging from $0.46 \pm 0.01$ to $0.57 \pm 0.04$. The GSI increased in every month from August to July.

Fecundity of $\boldsymbol{R}$. rita: The fecundity was found to vary from $37307.2 \pm 154.57$ to $60114 \pm 3207.88$ in fish samples weighing $810.87 \pm 49.75$ to $1081.35 \pm 74.52 \mathrm{~g}$ with ovaries weight ranging from $3.28 \pm 0.02$ to $6.17 \pm 0.78 \mathrm{~g}$ (Table 1).

Table 1. Fecundity counts at various lengths ranges and number of ova per kg body weight of $\boldsymbol{R}$. rita

\begin{tabular}{|c|c|c|c|c|c|c|}
\hline Frequency & $\begin{array}{c}\text { Length } \\
\text { range(cm) }\end{array}$ & $\begin{array}{c}\text { Mean total } \\
\text { length }(\mathrm{cm})\end{array}$ & $\begin{array}{c}\text { Mean body } \\
\text { weight }(\mathrm{g})\end{array}$ & $\begin{array}{c}\text { Mean ovary } \\
\text { weight }(\mathrm{g})\end{array}$ & $\begin{array}{c}\text { Mean } \\
\text { fecundity }\end{array}$ & $\begin{array}{c}\text { No. of ova/kg } \\
\text { body wt. }\end{array}$ \\
\hline 6 & $30-33$ & 31.98 & 810.87 & 3.28 & 37307.62 & 46058.02 \\
\hline 10 & $33-36$ & 34.73 & 964.51 & 4.51 & 46737.38 & 48684.37 \\
\hline 11 & $36-39$ & 37.72 & 1058.19 & 5.74 & 56267.21 & 53587.62 \\
\hline
\end{tabular}

Relationship between fecundity and total length: The linear relationship between log of fecundity and total length showed a positive correlation ( $r=0.9787)$ (Fig. 2). The regression equation of fecundity with total length of fish could be expressed as:

$\log _{10} Y=1.0546+2.3429 \log _{10} X \quad$ [Where, $Y=$ Fecundity, $X=$ Total length]

Relationship between fecundity and body weight: The logarithmic relationship of fecundity against body weight (Fig. 3) provided a positive linear correlation $(r=0.9545)$. The equation can be stated as:

$\log _{10} Y=0.3749+1.443 \log _{10} X \quad$ [Where, $Y=$ Fecundity, $X=$ Body weight]

A straight line through the origin would fit the points well, showing that the number of egg were directly proportional to the weight of the fish.

Relationship between fecundity and ovary weight: The fecundity increased progressively with ovary weight of the fishes (Fig. 4). The linear relationship between log fecundity and log ovary weight was positively correlated $(r=0.9874)$ :

$\log _{10} Y=4.196+0.7274 \log _{10} X \quad$ [Where, $Y=$ Fecundity, $X=$ Ovary weight]

\section{Annual changes in the ovary}

Development of ovary: Ovaries were internal, longitudinal and paired. A pair of mesenteries (mesovaria) suspended them dorso-laterally to the body cavity. This paired organ consisted of two ovarian lobes, which were separated by a septum. They were covered with an ovarian membrane and numerous ovarian lamellae, protected into ovarian cavity. The ovarian cavity connected the oviducts and the oviducts from each bilateral ovary joined to lead to the genital pore. The ovarian lamellae consisted of connective tissue lined by germinal epithelium, which contained cell nests of oogonia. Ovarian follicles developed along the lamellae and the vitellogenic oocytes were ovulated into the ovarian cavity. The follicles of vitellogenic and fully mature oocytes consisted of a transparent theca, granulosa and zona radiata. The size and extent of occupancy of the body cavity varied with the stage and condition of sexual maturity of the female. In initial stage, the ovaries were thin, elongated, slightly flattened and semi transparent in appearance. Gradually they took characteristic and specific colour and the middle portion of the two ovarian lobes became broader than the anterior and posterior region that was determined by monthly observation of ovaries. Immediately prior to breeding season, especially from May to June the ovaries became much expanded and occupied almost the whole cavity. The two ovarian lobes in $R$. rita were equal in size. The anterior part of the ovaries of $R$. rita was more or less triangular. The colour of the developing and maturing ovaries of $R$. rita was creamy, brownish and yellowish respectively. 


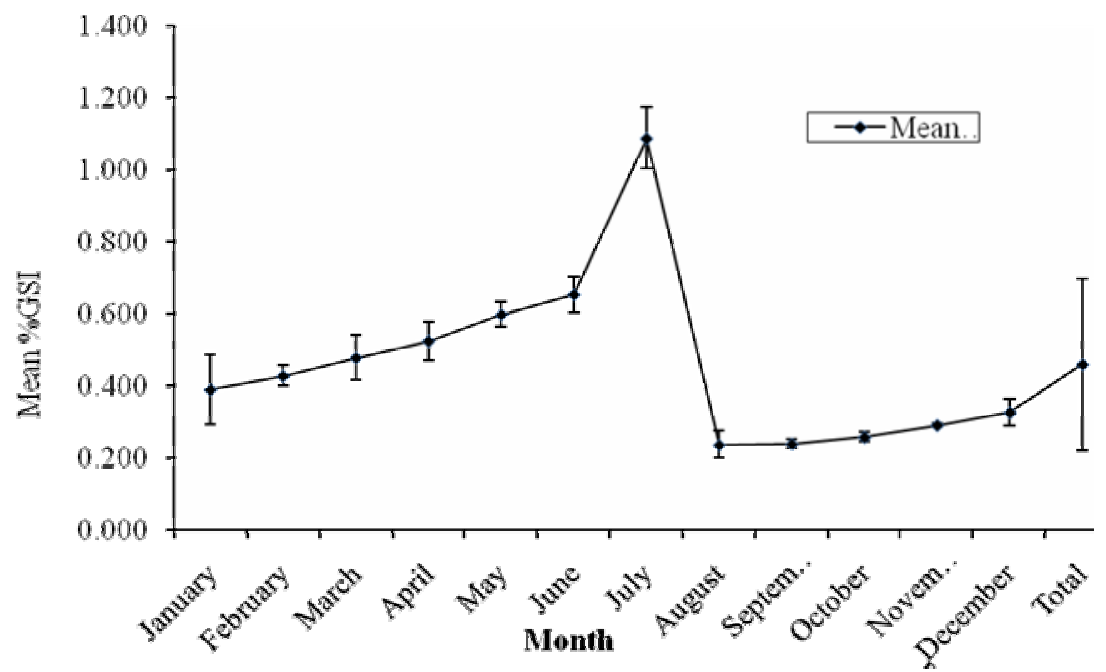

Fig. 1 Monthly variation of gonadosomatic index of female $R$. rita

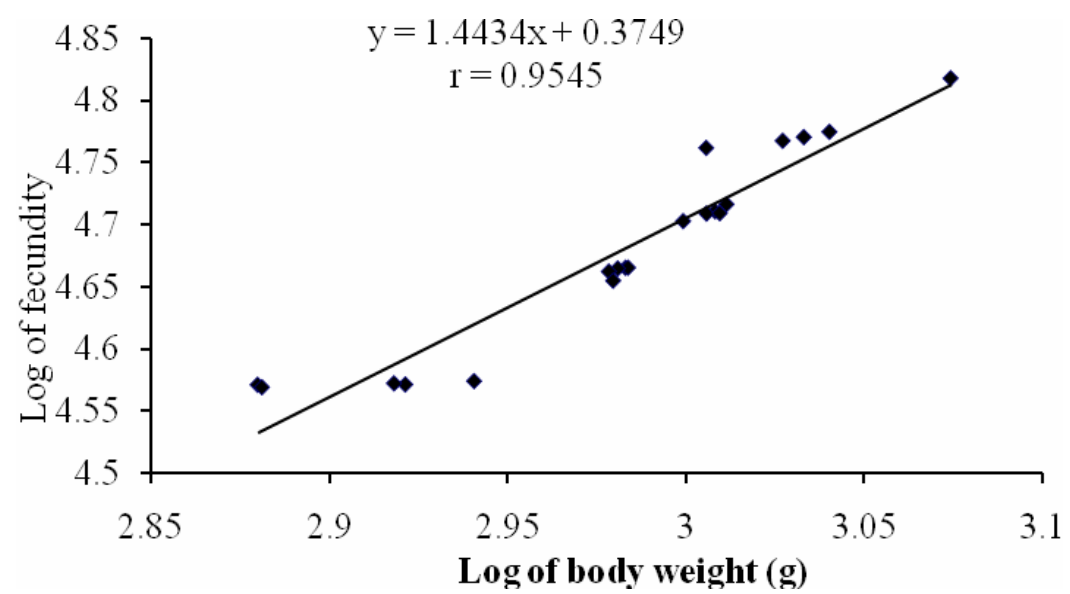

Fig. 2. Relationship between log of fecundity and log of total length of female $R$. rita

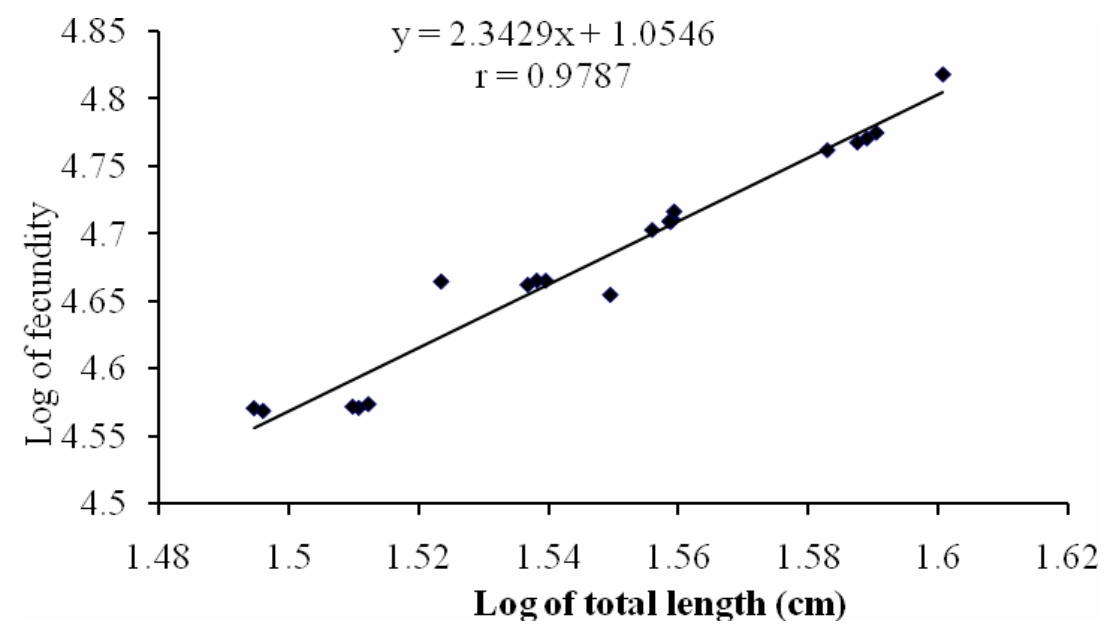

Fig. 3. Relation between log of fecundity and log of body weight of female $R$. rita 


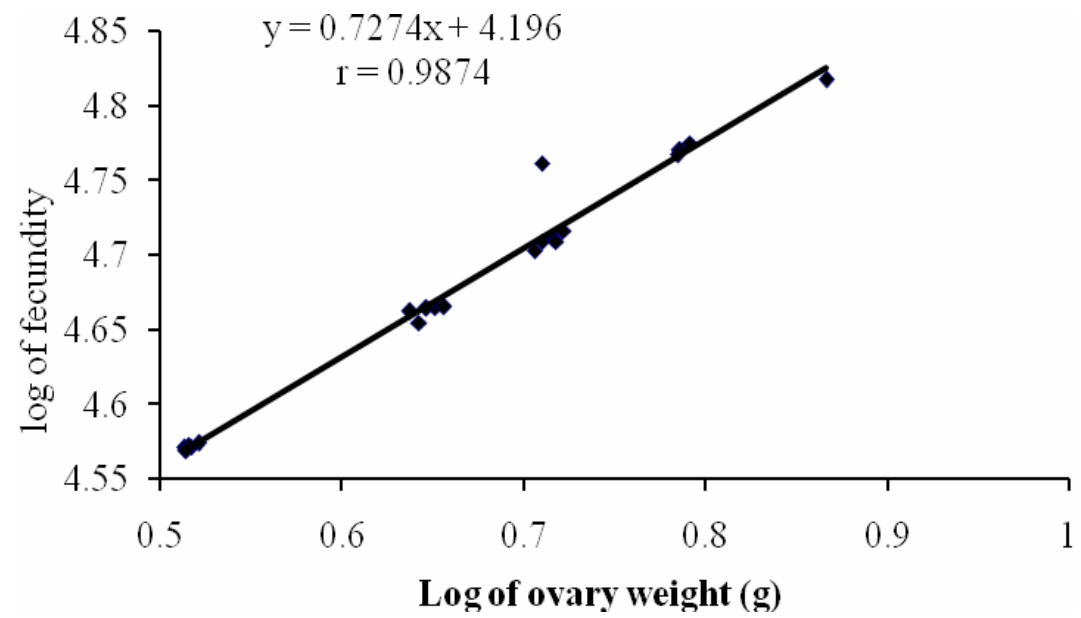

Fig. 4. Relationship between log of fecundity and log of ovary weight of $R$. rita

Histological observation of ovary: From the histological study of ovaries at successive months, it was observed that oocytes did not develop synchronously and oocyte at various maturation stages were observed in paired ovaries in the month of early year where most of the ova were developed and full of yolk in the middle. In the present study, maturation stages of oocytes that indicates ovarian development in female $R$. rita shown in Figs. 5 (A, B, C, D, E, F).

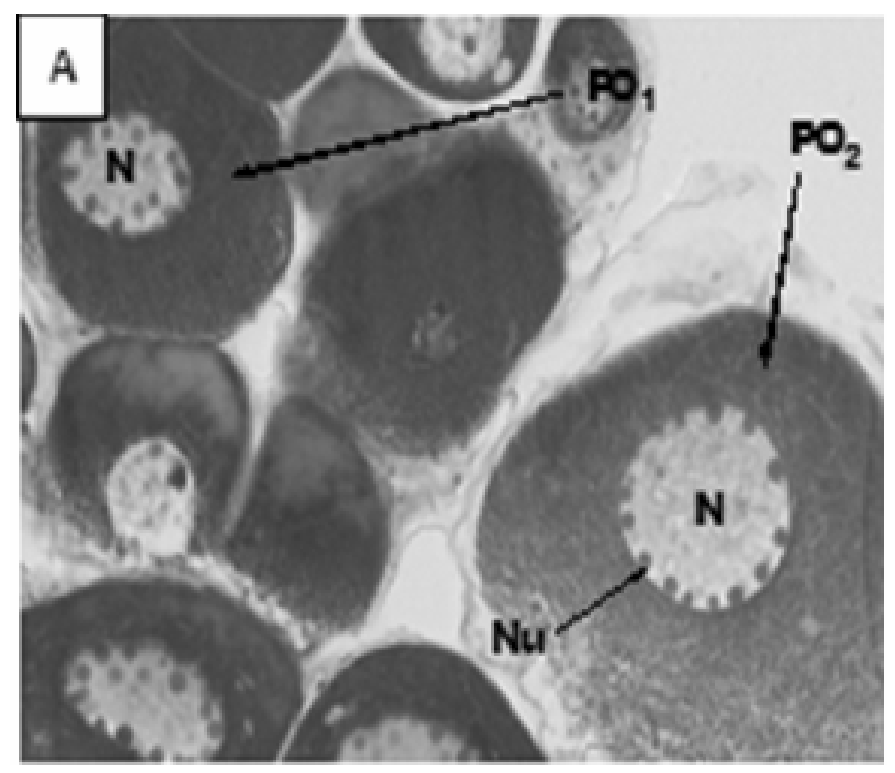

Fig. 5A. Photomicrograph of a cross section of a rita ovary Early $\left(\mathrm{PO}_{1}\right)$ and Late $\left(\mathrm{PO}_{2}\right)$ perinucleolar stage of oocytes in the ovary of Rita rita in January and February. $\mathrm{N}=$ Nucleus with nucleoli (Nu) [Haematoxyline and eosin (H\&Ex200)] 


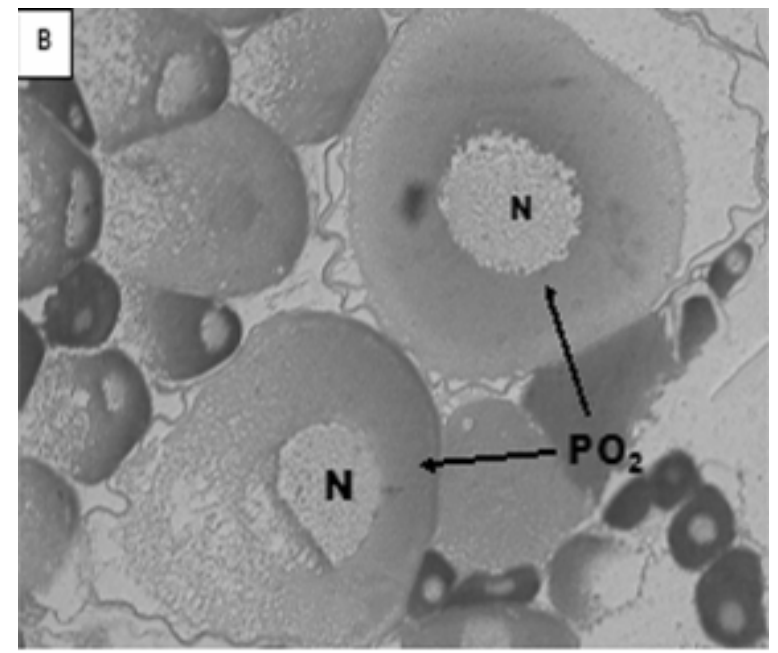

Fig. 5B. Late perinucleolar stage of oocytes $\left(\mathrm{PO}_{2}\right)$ in the ovary of Rita rita in March and April. $\mathrm{N}=$ Nucleus with nucleoli $(\mathrm{H} \& \mathrm{E} \times 200)$

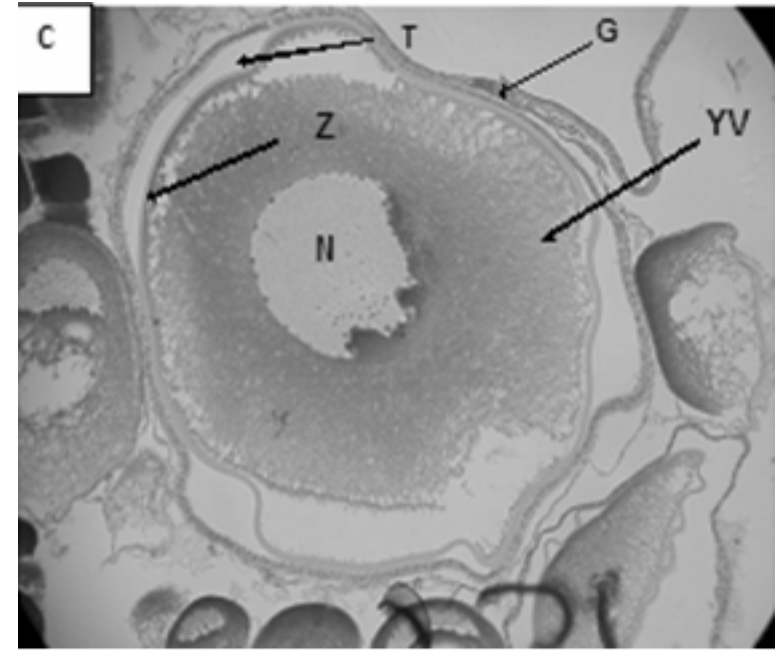

Fig. 5C. Yolk-vesicle stage of oocytes (YVO) in the ovary of Rita rita in May. T: theca, G: granulosa, Z: zona radiate (H\&E×200)

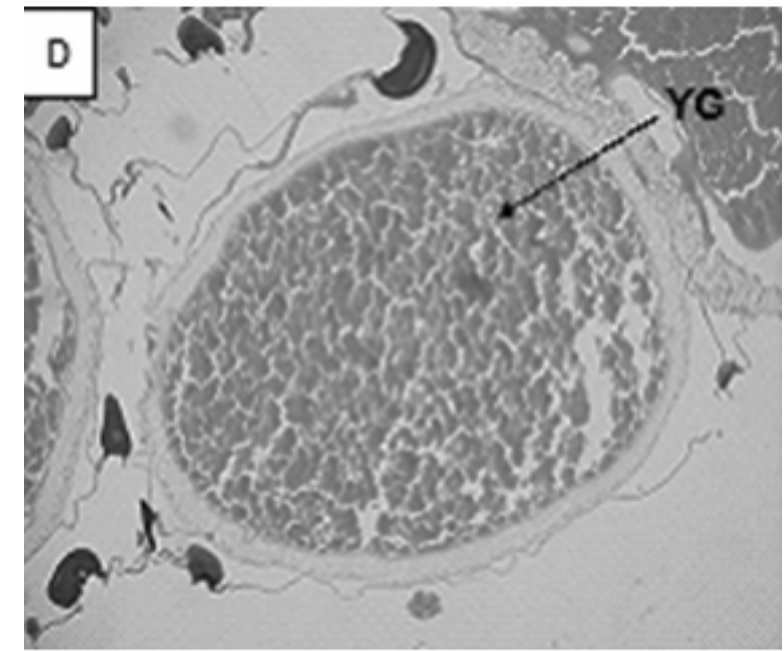

Fig. 5D. Early yolk-granule stage of oocytes (EYGO) in the ovary of $R$. rita in June 


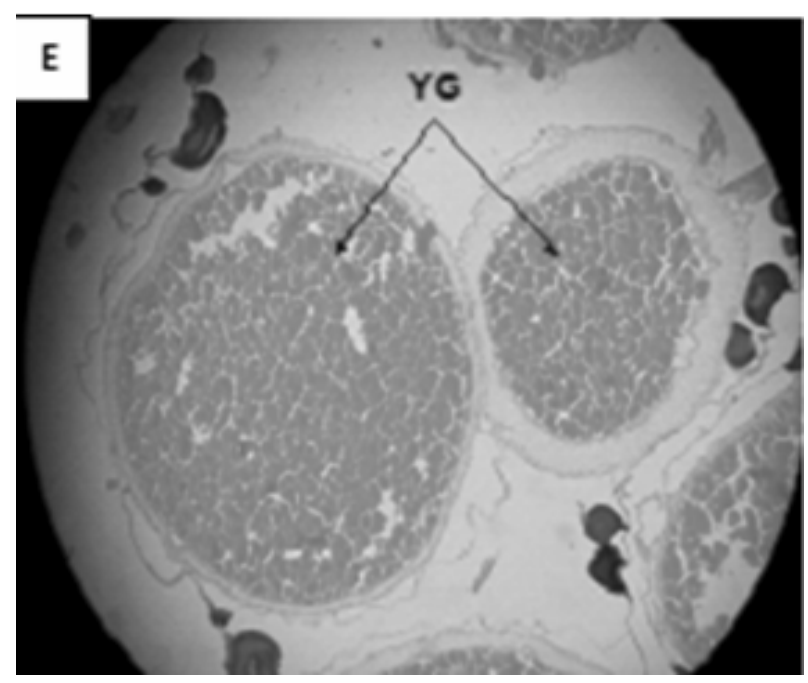

Fig. 5E. Late yolk-granule stage of oocytes (YGO) in the ovary of $R$. rita in July

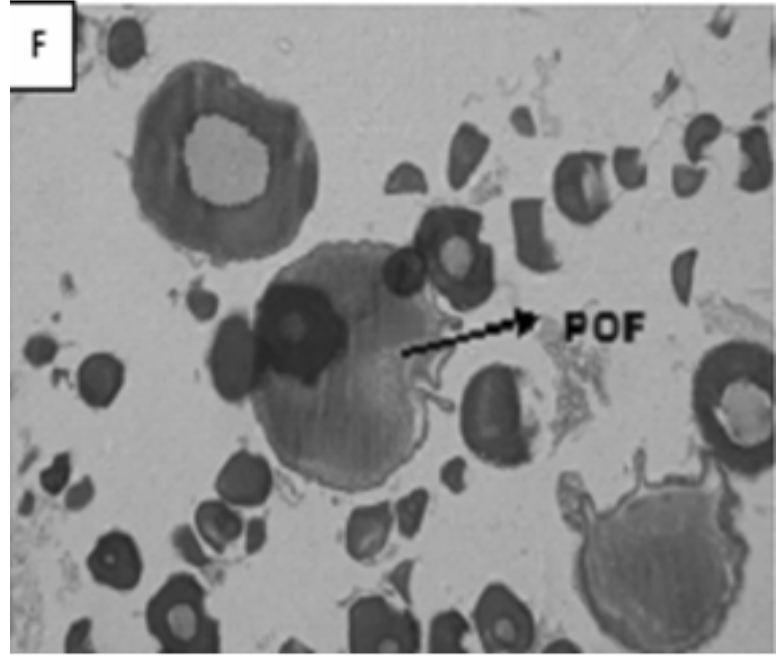

Fig. 5F. Spent phase in the ovary of Rita rita in August (H\&E×200). POF- Post Ovulatory Folicle

\section{Discussion}

The mean GSI values throughout the year during the study period showed the existence of one breeding season in Rita rita. The histological observations of monthly samples of ovary confirmed this finding. The GSI was calculated from January to December. There was a gradual rise in the values from April to July. The highest gonado-somatic index of $R$. rita was $0.57 \pm 0.03$ in July and the second highest was $0.51 \pm 0.00$ in June, indicating that $R$. rita may breed in June and July.

Fecundity may be expressed in terms of the number of eggs produced per brood fish in a breeding season (Lagler, 1949). It is sometimes referred to as total or absolute fecundity or more usually just as fecundity (Heese, 1990). The fecundity of $R$. rita varied from $37307 \pm 154$ to $60114 \pm 3207$ for the fish length from $31.97 \pm 0.63$ to $38.91 \pm 0.59 \mathrm{~cm}$ and weighing from $810.87 \pm 49.75$ to $1081.35 \pm 74.51 \mathrm{~g}$. Azadi et al. (1987) recorded the fecundity to vary from 5,683 to 21,922 for Heteropneustes fossilis and relationship of fecundity-body length, fecundity-body weight and fecundity-ovary weight was found to be linear relationship. The present study also indicates that $R$. rita belonging to the same size group had varying number of eggs in their ovaries.

Azadi and Siddique (1986) also reported a linear relationship between fecundity-body length, fecunditybody weight, fecundity-standard length and fecundity-ovary weight for catfish Heteropneustes fossilis which is consistence with the present study. The relation between fecundity and ovary weight were found to be the most prominent among all the relationships and the correlation coefficient, $r(0.9874)$ between fecundity and ovary weight was highly significant $(P<0.01)$. These findings agree with the findings of Das et al. (1989) for Heteropneustes fossilis.

Histological observation shows the evidence of gonadal maturation and spawning season. Reproductive prospective of a population is one of the basic needs to designate the individuals of that population in respect to their gonadal conditions (Jhingran \& Verma, 1972).

Ovarian development of $R$. rita was examined to study the pattern and timing of growth phase and maturation stages of germ cells in the gonad of female. It was observed that fish exclusively in immature stages (early and late perinucleolar stage oocytes) of maturity was mostly available in the months from January to April. Yolk- vesicle stage oocytes appeared in the month of May. Both yolk vesicle and yolk granular stages were found in the month of June but most of the eggs in the month of July were in yolk granule stage. These findings agree with the findings of Mollah (1986) reported for another catfish, 
Clarias macrocephalus. Karamchandi \& Motwani (1955) concluded from the larvae and juveniles collected during July and August that the fish most probably breed in the river Ganga from March to August. Finally it may be assumed that $R$. rita may breed in the months of June and July in the river old Brahmaputra in Bangladesh.

\section{Conclusion}

This study will be helpful for an aquaculturist who will try to breed $R$. rita by artificial or induced breeding technique. However, a complete picture of breeding season of $R$. rita can be obtained if samples from other river systems hosting $R$. rita are collected and studied similarly.

\section{Acknowledgements}

This work was made possible by the financial assistance of the University Grants Commission (UGC). The authors are also grateful to the Department of Aquaculture, Bangladesh Agricultural University, Mymensingh, Bangladesh for providing the laboratory facilities to the preparation of histological slides.

\section{References}

Azadi, M. A., Islam, M. A. and Dev, S. R. 1987. Some aspects of the biology of Mystus vittatus (Bloch): I. Food and feeding habits and fecundity. Bangladesh Assoc. Adv. Sci., Dhaka (Bangladesh). Abstract of the $12^{\text {th }}$ Annual Bangladesh Sci. Conf. Sec. 2, Dhaka (Bangladesh), 36pp.

Azadi, M. A. and Siddique, M. S. 1986. Fecundity of catfish (in Bangladesh) Heteropnuestes fossilis (Bloch). Bangladesh J. Zool., 14: 33-39.

Das, M., Dewan, S. and Debnath, S. C. 1989. Studies on fecundity of Heteropneustes fossilis (Bloch) in a mini pond of Bangladesh Agricultural University, Mymensingh. Bangladesh J. Agril. Sci., 16:1-6.

Devi, N. T., Khumar, F. and Siddiqui, M. S. 1991. Observations on the morphometric characters of the catfish Rita rita (Ham.) of the river Yamuna. J. Inland Fish. Soc. India, 23: 52-58.

Faruq, M. A., Saha, J. K., Miah, M. I. and Rahmatullah, S. M. 1996. The fecundity of Clarius batrachus (Linnaeus) and the relationship of fecundity with length and weight. Bangladesh J. Fish., 19:67-70.

Heese, T. 1990. Gonad development and fecundity of whitefish, Coregounus lalaretus (Linnaeus) from the pormeranian Bay. ActaIchthyologica-et-Pascutoria, Poland, 20: 3-12.

Humason, G. L. 1972. Animal tissue techniques. W. H. Freeman and Co., Sanfrancisco, CA., 614 pp.

Islam, M. S. and Hossain, M. A. 1990. The fecundity and sex ration of the common punti, Puntius stigma (Cuvier and Valenciennes) (Cypriniformes: Cyprinidae) from the river Padma near Rajshahi (in Bangladesh). Rajshahi Univ. J. Zool., 9:69-74.

IUCN, Bangladesh., 2003. Bangladesher Bipanno Prani. IUCN. The World Conservation Union. 294 pp.

Jhingran, V. G. and Verma, D. N. 1972. Sexual maturity and spawning of Gudusia chapra (Ham.) in Ganga river system. Proceeding of National Science Academy, India, 40: 207-224.

Karamchandi, S. J. and Motwani, M. P. 1955. Early life history bionomics and breeding of Rita rita (Hamilton). J. Zool. Soc. India, 7:115-126.

Khan, M. S. A., Alam, M. J., Rheman, S., Monda, S. L. and Rahman, M. M. 2002. Study on the fecundity and GSI of Bcrakishwater Catfish Plotosus canius (Hamilton-Bucchanan). Online J. Bio. Sci., 2: 232-234.

Lagler, K. F. 1949. Studies in freshwater fishery biology. Ann. Arbor. Michigan, 119 pp.

Lagler, K. F. 1956. Freshwater fishery biology. $2^{\text {nd }}$ edition. W. M. C. Brown Company, Dubuque, lowa, 421 pp.

Mollah, M. F. A. 1986. Cyclic changes in the ovary of freshwater catfish, Clarias macrocephalus (Gunther). Indian J. Fish., $33:$ 54-65.

Sarker, P. K., Pal, H. K., Rahman, M. M. and Rahman, M. M. 2002. Observation on the Fecundity and Gonadosomatic Index of Mystus gulio in Brackishwater of Bangladesh. Online J. Bio. Sci., 2: 235-237.

Zar, J. H. 1984. The analysis variance and multiple comparison. In: Statistical Analysis (ed. Kurtz B.). Prentice-Hall. Englewood clitfs, NJ, USA. pp. 162-233. 